\title{
THE INTERCULTURAL DIMENSION OF MILITARY ACTION FOR COMBATING HYPOTHETICAL ADVERSARIES
}

\author{
Paul TUDORACHE*, Lucian ISPAS** \\ *National Defence University, Bucharest, Romania \\ **"Nicolae Bălcescu" Land Forces Academy, Sibiu, Romania \\ tudorache@yahoo.com, ispaslucian04@yahoo.com
}

\begin{abstract}
Defining and analyzing the current typology of threats determines the military structures to operationally and, implicitly, organizationally adapt in order to ensure their ability to deter and combat hypothetical opponents in any operational environment. From the point of view of efficiency and effectiveness of action, it is no longer sufficient to engage the joint and multinational military structures alone, inter agency and intergovernmental action approaches being necessary. On these grounds, the intercultural dimension of the action of the military structures undergoes changes, moving from the internal plan, of the inter force relationships in the organic structure of the multinational military force into the external one, defined by the interactions between the latter and the structures/forces/elements within other agencies, intergovernmental organizations, to which the local population is added.
\end{abstract}

Keywords: intercultural dimension, hypothetical opponents, JIIM type actions, cultural capability

\section{Introduction}

The current operational environment, whose factors of influence are represented by complexity, uncertainty/unpredictability, access to vital resources, population as a center of gravity, urbanization, population migration [1], etc., calls for the full spectrum of operations (Full Spectrum Operations - FSO) in order to be able to combat the hypothetical opponents of the current typology. After studying the specialized literature, a generic classification of hypothetical opponents can be given as follows: state actors, chronically fragile states (states that put pressure on modern states by encouraging and supporting radical/extremist tendencies or by developing and threatening to use nuclear capabilities), failed/on the brink of failing states (states that do not cope with the negative influences of globalization, demography, climate change, lack of resources) and non-state actors (illegal entities, extremist interest groups, transnational criminal gangs, etc.) [2]. Even though the armies, in general, and those in NATO, in particular, have united their efforts to counter the current threats by creating and engaging multinational military structures, the capability of hypothetical opponents to equally use conventional and unconventional modes of action makes it difficult to combat them, generating a number of requirements in terms of organizational and actional adaptation of the military forces.

2. Addressing the intercultural dimension from the perspective of the type JIIM action

In terms of action adaptation, military structures, in general, and the multinational 
ones, in particular, had to rethink their action possibilities from a more comprehensive perspective, such as joint, interagency, intergovernmental, multinational action (Joint, Interagency, Intergovernmental and Multinational (JIIM).Thus, the concept of the intercultural dimension applied to the current military operations has undergone some changes because its approach only from a joint and multinational perspective (as it was until recently) is no longer relevant, and it must also be equally related to the interagency, intergovernmental issues, as well as to those specific to the local population and to the other actors of the operational environment. In this respect, a definition of the intercultural dimension of the action of the multinational military structures is as follows: "the whole of the co-operations and interactions between the personnel belonging to the various national military forces in the organic structure of the multinational military force, the forces/structures belonging to other intergovernmental agencies, organizations, the local security forces, the local population (including the local leaders and local government bodies) and other actors in the operational environment that can potentiate or diminish the effectiveness and efficiency of planning and executing the multinational military operations"[3]. We note that in order to achieve high actional performance (efficiency and effectiveness), military structures should have and engage as many capabilities as possible from as many different environments as possible.

On the other hand, the spectrum of the JIIM type actional approach equally covers the maneuver, fire and effects (MFE), the operational support (OS), and force sustainment (FS). A graphical representation of the specifics of the actions of the military structures deployed to deter and combat hypothetical opponents at all levels (tactical, operative, and strategic) on the three directions (MFE, OS, FS) is presented in the figure below.

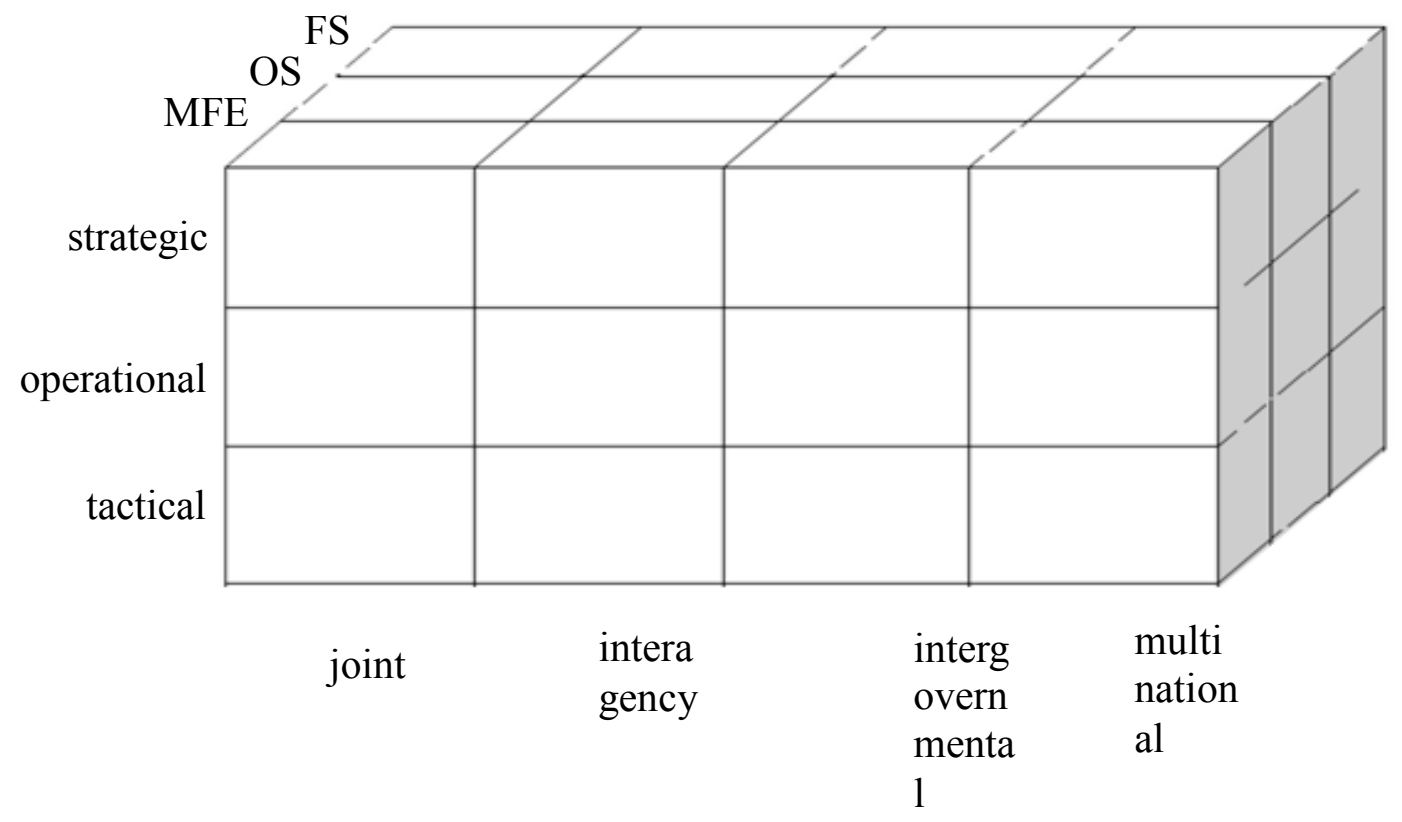

Figure no 1.Nature of military actions for combating hypothetical opponents [4]

A question is certainly being configured: What are the requirements for the intercultural dimension of military action to positivelymanifest itself during the fight against hypothetical opponents? Regardless of the level of military actions, the 
requirements of the intercultural dimension of the current military actions involve a series of knowledge (marked as C), skills (marked as D) and abilities (marked as A) specific to each domain within the JIIM (Table no.1).

Table no. 1 Knowlede, skills, abilities specific to the intercultural dimension of military action on domains within JIIM [5]

\begin{tabular}{|c|l|}
\hline \multirow{2}{*}{ Joint } & $\begin{array}{l}\text { joint militarycapabilities and specificdoctrine (C); } \\
\text { joint processes and organizational structure (C); } \\
\text { joint planning system and processes (C); } \\
\text { management of financial resources (D); } \\
\text { originality (A). }\end{array}$ \\
\hline processes, cultureand capabilities specific to governmental \\
agencies (C); \\
cultural meta-knowledge (C); \\
governmental policy and strategy (C); \\
governmental laws, policies and processes for the allotment of \\
resources (C).
\end{tabular}

Among the above-mentioned requirements, whose umbrella covers all levels of military action, specific to the tactical action are the following:

- regional expertise;

- doctrine and theory regarding the typology of military operations;

- cultural meta-knowledge;

- use of military capabilities (interarms and joint);

- establishing relationships with the personnel of other nations;
- linguistic skills (the English language, the local population language);

- stress management;

- self conscienciousness;

- joint interforce instruction[6].

The cultural meta-knowledge, regional expertise, relations with other nations' personnel and language skills (only from the perspective of the local population) can be found in the concept of cultural capability whose components are: language, 
regional expertise and intercultural competence. The first two refer to the culture of the area of operations, being addressed within pre-displacement training, while the last component, intercultural competence, covers general culture and is the subject of continuous training throughout the whole career.

3. Culturalcapability - multiplier of intercultural dimension during planning and execution of operations

The formation and development of a cultural capability at the level of military structures (all personnel, regardless of the occupied position) may represent a solution for multiplying the positive manifestation of the intercultural dimension in the

Table no 2.Adaptation of the process of planning the operation for combating asymmetric threats[7]

\begin{tabular}{|c|c|c|}
\hline Cultural imperatives & Steps & Cultural imperatives \\
\hline Cultural evaluation & 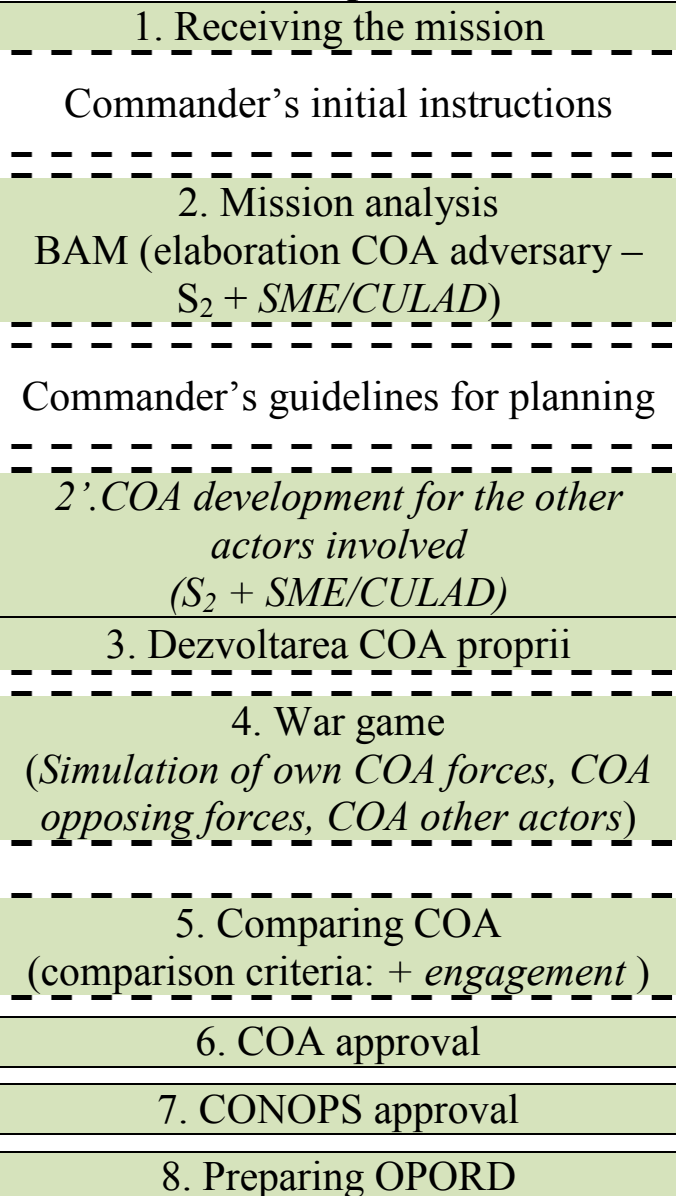 & 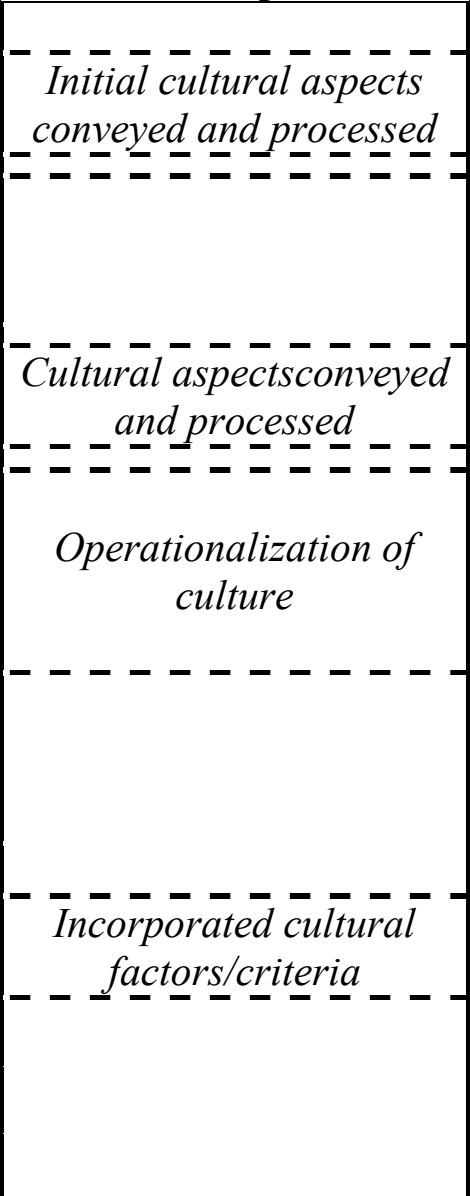 \\
\hline
\end{tabular}

Legend: italic - proposal

Concerning the stage of the military operation, some ways in which cultural capability can support it are: the integration of the socio-cultural aspects in battle rhythm conduct of military operations, irrespective of the specifics of the opponent. Its applicability covers the planning and execution of operation as well. From a planning perspective, taking into account the factors of influence of operational environments and the nature of current conflicts (correlating conventional and nonconventional combat actions), the current planning process (the decision-making process) should be adapted by integrating the socio-cultural (dynamic) aspects in all its phases. In the table below, we present a variant of the decision making process that can be used to combat hypothetical opponents. 
For both phases of the military operation, cultural capability is a solution as it allows the commandments and maneuver forces to operationalize the culture that involves integrating socio-cultural aspects into all phases of planning and executing the operation.

\section{Conclusions}

For the military structures whose cultural diversity is characteristic, some of the effects of the positive manifestations of the intercultural dimension during the FSO can be: increased planning, command and control; enhanced actional capacity (based on the synergistic effect of the effort of different actors); capabilities to anticipate/identify the opponent's actions, and to exploit improved opportunities as well; capabilities to identify, minimize and manage the amplified risks.
All these effects of the intercultural dimension significantly contribute to improving the actional efficiency and effectiveness of military structures, an essential requirement to combat hypothetical opponents. Both the efficiency and effectiveness should not be determined only from the perspective of military operations. One way of comprehensive determination is the multidirectional one, involving measurements in relation to the beneficiaries and the other parties involved. More specifically, determining the overall effectiveness and efficiency of a military operation involves measuring it from the perspective of military structures (command, maneuver forces), local population (as beneficiary of military operations) and, last but not least, of forces/structures within other agencies, intergovernmental and non-governmental organizations.

\section{References}

[1] FINABEL Study nr T.38.R, The Future Operational Environment, its Impact on the Different Components, the Role of Land Forces and Priorities to Be Given as Far as Force Engagement is Concerned, Granada, Spain, December 2010, pp. 6-9.

[2] Multinational Interoperability Council (MIC), Coalition Building Guide ( $3^{\mathrm{RD}}$ edition), Future Coalition Operating Environment: Interoperability Challenges For The Future, 7 November 2012, pp. 16-17.

[3] Paul Tudorache, Fundamente teoretice și practice privind dimensiunea interculturală a acțiunii structurilor militare multinaționale, Editura Academiei Forțelor Terestre „Nicolae Bălcescu”, Sibiu, 2018, p. 18.

[4] Markel M. Wide, Henry A. Leonard, Charlotte Lynch, Christina Panis, Peter Schirmer, Carra S. Sims, Developing U.S. Army Officers' Capabilities for Joint, Interagency, Intergovernmental and Multinational Environments, Rand Corporation, 2011, p. 24-3.

[5] Ibidem, p. 24-6.

[6] Ibidem, p. 24-7.

[7] Paul Tudorache, Capabilitatea culturală - cerință a performantei structurilor militare multinationale în contextul mediilor operationale specifice secolului al XXI-lea, Editura Academiei Forțelor Terestre „Nicolae Bălcescu”, Sibiu, 2017, pp. 46-47.

[8] Multinational Experiment 6 (MNE 6), Obj.4.3: Cross-Cultural Awareness, 01 November 2010, Granada/Spain, pp. 29-31. 